\title{
Influence of Column Characteristics on Retention and Selectivity in RP-HPLC
}

by L. Szepesy / V. Háda

published in 2001, 53, pp $99-108$

In Figure $1(\mathrm{a}, \mathrm{b})$ the regression coefficients were printed incorrectly. Please find below the correct version of Figure $1(\mathrm{a}, \mathrm{b})$.
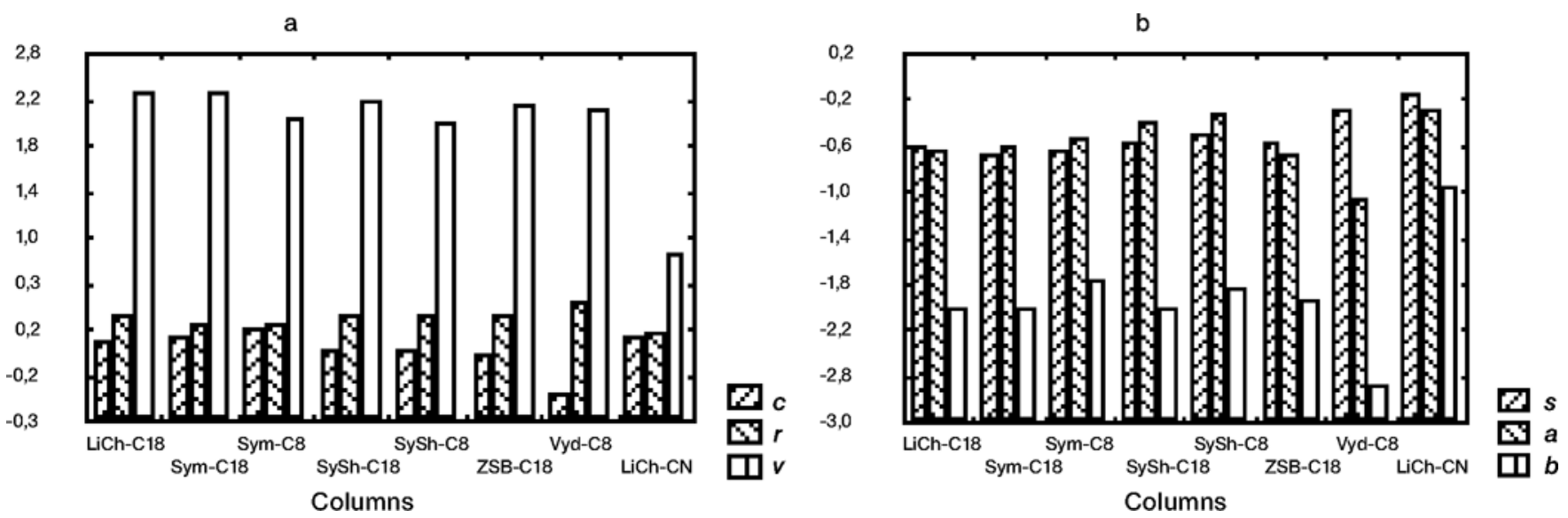

Figure 1. a Regression coefficients of the LSER equation increasing solute retention. b Regression coefficients of the LSER equation decreasing solute retention. 